\title{
RAMÍREZ GONZÁLEZ, S. (2018). LA SALA UNICAJA DE CONCIERTOS MARÍA CRISTINA DE MÁLAGA. EVOLUCIÓN HISTÓRICA Y PATRIMONIO ARTÍSTICO. MÁLAGA: SERVICIO DE PUBLICACIONES DE LA FUNDACIÓN UNICAJA
}

\section{RAMÍREZ GONZÁLEZ, S. (2018). THE MARIA CRISTINA OF MALAGA UNICAJA CONCERT HALL. HISTORICAL EVOLUTION AND ARTISTIC HERITAGE. MÁLAGA: PUBLICATIONS SERVICE OF THE UNICAJA FOUNDATION}

\author{
Iluminada Rodríguez Morgado \\ (Universidad de Málaga, España) \\ irodriguezmorgado@gmail.com
}

Recibido: 01 de septiembre 2020 / Aceptado: 08 de septiembre 2020

"Nunca se alcanza la verdad total, ni nunca se está totalmente alejado de ella". Citando a Aristóteles, queremos enunciar la idea principal que subyace tras el análisis de la obra protagonista de esta reseña, realizada por Sergio Ramírez González, doctor en Historia del Arte y profesor titular del grado homónimo de la Universidad de Málaga. Y afirmamos esto porque, en cada una de las ideas vertidas por el doctor Ramírez, se atisba la obligación y necesidad de los investigadores e investigadoras de revisar, reinterpretar y otorgar nuevas y valiosas visiones sobre aseveraciones tradicionalmente aceptadas, mediante refutaciones. A ello debemos sumar la relevancia que tiene el patrocinio de instituciones a través de la publicación de trabajos que defienden una correcta difusión cultural, caso de la Fundación Unicaja.

Por todo, podríamos definir a La Sala Unicaja de Conciertos María Cristina de Málaga. Evolución histórica y patrimonio artístico, como un pensado compendio de aquellos estudios más representativos en torno al inmueble. Cabe añadir, asimismo, el 
innovador tratamiento de nuevas informaciones en torno a diferentes temáticas, seguido de un riguroso análisis de asuntos históricos, sociales, políticos y artísticos.

De este modo, esta obra se encuentra nutrida de citas a autores y autoras de referencia como Guillén Robles, Ángel Caffarena, Enrique Atencia, Marion Reder, Rodríguez Marín o Teresa Sauret. Estas complementan explicaciones que parten de lo general a lo particular, siendo amena y eficaz la comprensión de las mismas. Además, presenta una encomiable contextualización de las diferentes vicisitudes acaecidas no solo en el inmueble, sino relativas al entorno social, urbanístico y a los personajes próximos al mismo. Por tanto, observamos una distribución coherente, a la par que necesaria, con una primera parte dedicada a un conveniente encuadre de la Málaga barroca, que acogía un monasterio franciscano malacitano, el de San Luis el Real, que finalmente se convertiría en el contenedor de la sala cultural, tras una densa historia de remodelaciones protagonizada por diversas instituciones. Nos referimos al Liceo artístico, científico y literario y, posteriormente, a la Sociedad Filarmónica y al Real Conservatorio de Música María Cristina, que actuaron sobre la sala a lo largo del siglo XIX, atendiendo a cuestiones variadas que quedan reflejadas a lo largo de la obra de Ramírez González. Con la posterior adquisición, ya en los años setenta del siglo pasado, por parte de la Caja de Ahorros de Ronda (hoy fusionada con el Monte de Piedad, formándose así Unicaja), la sala fue restaurada con la intención de dotarla de función cultural.

Además de exhibir las diferentes transformaciones y los variopintos avatares históricos que conforman la actual sala, custodiada por la Fundación Unicaja, Ramírez dedica una segunda parte del libro, conforme a su propia disciplina, al análisis concienzudo del patrimonio histórico-artístico de la Sala María Cristina. Por ello, encontramos un estudio formalista, iconográfico y estilístico sustancial, próximo a los estudios culturales, que proporcionan la comprensión del conjunto inmueble como resultado de una meditada reflexión por parte de quienes decidieron remodelarlo, destacando las pinturas de artistas sobresalientes como José Nogales, Denis Belgrano y Joaquín Martínez de la Vega.

Sin duda, concebimos que esta obra recalca la importancia que tiene el patrimonio como transmisor de aquellos asuntos que, a priori, pueden pasar desapercibidos. Es la arquitectura la que se muestra parlante, pero a la vez discreta, siendo labor del historiador e historiadora del arte descifrarla y manifestar aquellos asuntos que aparecen velados. 
Afortunadamente, este exhaustivo trabajo de estudio e investigación brilla gracias a la revelación que en él se encuentra acerca de una información concerniente a la localización real de la Sala de Conciertos dentro del entramado religioso franciscano. Pese a que, por heredad, se ha considerado que esta sala se hallaba en la antigua iglesia del conjunto monacal, los estudios del profesor Ramírez apuntan a un error, tras visionar diferentes planos. Esto lo lleva a afirmar que dicha sala se encuentra erigida próxima a la que fuera el ala oeste del claustro principal y a la huerta conventual, por lo que Ramírez desmonta la teoría históricamente aceptada, ya que la iglesia se ubicaba alejada del emplazamiento de la sala y, además, su orientación era opuesta a la misma. Todo ello se ratifica gracias a una reproducción de los planos que consolidan un excelente trabajo de campo, a lo que acompaña la cuidada selección de aquellos documentos y fotografías en este manual que, de esta manera, está al alcance de cualquier tipo de público. En este sentido, el vocabulario empleado es, como se espera en los temas tratados, formal y científico, pero a la vez cercano, por lo que su lectura es amena, indiferentemente de la formación académica del lector. La introducción de un completo repertorio visual, de notas a pie de página contenedoras de aclaraciones y citas bibliográficas sólidas avalan la pulcritud científica requerida en una investigación de esta envergadura, por lo que se trata de un estudio recomendable para cualquier persona interesada en la cultura patrimonial malagueña. Con todo, es ineludible hacer alusión a la tesis doctoral de Ramírez, centrada en inmuebles seráficos malacitanos, ya que es un buen punto de partida y una recomendación, sin lugar a dudas, para comprender la confección de la obra que hoy comentamos.

En definitiva, detectamos en este estudio sobre la Sala María Cristina un gran trabajo recopilatorio de todo tipo de fuentes y que, además, incluye una novedosa visión de un inmueble desconocido por la mayoría, pese a que fue uno de los centros culturales más importantes de Málaga. Por ello, es un aporte significativo a la historia de la ciudad, que gracias a piezas bibliográficas como esta se magnifica y se declara como digna de interés y elogio patrimonial. 